\title{
The feasibility and acceptability of a population-level antenatal risk factor survey: Cross-sectional pilot study
}

Running head: Piloting an antenatal risk survey

Manuscript type: Original Article

Dr Anna MH Price

Murdoch Childrens Research Institute, and the Centre for Community Child Health, The Royal Children's Hospital.

in

4

Murdoch Childrens Research Institute, and the Centre for Community Child Health, The

Royal Children's Hospital.

50 Flemington Road, Parkville, VIC 3052, Australia

hannah.bryson@mcri.edu.au

Dr Fiona Mensah

Murdoch Childrens Research Institute, Clinical Epidemiology and Biostatistics Unit, The Royal Childrens Hospital, and The Department of Paediatrics, The University of Melbourne. 50 Flemington Road, Parkville, VIC 3052, Australia

fiona.mensah@mcri.edu.au

Prof Lynn Kemp

Translational Research and Social Innovation, Western Sydney University.

Parramatta NSW 2150, Australia

lynn.kemp@,westernsydney.edu.au

Dr Lara Bishop

Australian Research Alliance for Children and Youth.

Canberra City ACT 2601, Australia

lara.bishop@mcri.edu.au

Prof Sharon Goldfeld (corresponding author)

Murdoch Childrens Research Institute, the Centre for Community Child Health, The Royal Children's Hospital and The Department of Paediatrics, The University of Melbourne.

50 Flemington Road, Parkville, VIC 3052, Australia

+61393456408

sharon.goldfeld@rch.org.au

This is the author manuscript accepted for publication and has undergone full peer review but has not been through the copyediting, typesetting, pagination and proofreading process, which may lead to differences between this version and the Version of Record. Please cite this article as doi: $10.1111 /$ jpc.13510

This article is protected by copyright. All rights reserved. 
Piloting an antenatal risk survey

ABSTRACT

Aim: Australian data on the prevalence and distribution of antenatal risk factors are scarce. This study aimed to investigate (1) the feasibility and acceptability of an antenatal risk factor survey collected in public settings, and (2) whether the survey risk factors co-occur with more sensitive risk factors that are privately-asked by clinicians.

Methods: Design \& Setting: Study-designed survey linked with clinician-collected risk factors. Participants: Pregnant women attending antenatal clinics at two Victorian hospitals. Measures: (a) Study-designed survey: young pregnancy, no support, poor/fair/good general health, anxious mood, not finishing high school, no income, long-term illness, living without another adult, not employed, never had a job, and proxy poverty measures; (b) Cliniciancollected data: smoking, alcohol/marijuana/drug use, domestic violence, social issues, history of mental health problems, and depression symptoms. Analyses: (1) Feasibility and acceptability were assessed through survey completion. Each item was assessed for whether they discriminated risk; dichotomized into risk versus no risk; with a total count calculated.

(2) Co-occurrence was assessed by examining how the risk factor count agreed with clinician-collected items.

Results: 166/186 (89\%) of eligible women completed the survey; 139/166 (84\%) consented to linking clinician-collected data. The high response and zero missing data demonstrated feasibility and acceptability. Of women with linked data, 92/139 (66\%) had e 1 survey risk factor and 30/139 (22\%) had e 3; 36/139 (26\%) had at least one co-occurring cliniciancollected risk factor.

Conclusions: This survey provides a simple, rapid approach to gathering antenatal risk data publicly. It may be a helpful addition to clinicians' standard history collection.

Keywords: maternal health services; pregnancy; risk factors; screening; socioeconomic factors

Abbreviations: EPDS: Edinburgh Postnatal Depression Scale; EMR: Electronic Medical Record; RCT: Randomized Controlled Trial; SEIFA: Socio-Economic Indexes for Areas; SF: Short-Form; SNHV: Sustained nurse home visiting 
Piloting an antenatal risk survey

\section{Significance}

\section{What's Known on this Subject?}

Understanding antenatal maternal risk factors allows health professionals to allocate services. However, published antenatal risk factor data for Australian women are scarce. There is a need for a simple, acceptable risk factor survey that can be feasibly collected at the population-level.

\section{What This Study Adds:}

A survey of ten antenatal risk factors is acceptable to women and feasible to collect in public settings. The survey identifies most women who report other risk factors (e.g. substance use, domestic violence) that may be less acceptable to ask or can only be asked privately. This survey could be a helpful addition to clinicians' standard history collection.

This article is protected by copyright. All rights reserved. 
Piloting an antenatal risk survey

\section{INTRODUCTION}

The links between women's antenatal risk factors and children's learning and development trajectories are well-documented ${ }^{1-6}$. Antenatal risk factors can be broadly divided in two groups: those pertaining to the intrauterine environment (e.g. alcohol, tobacco, illicit drugs ${ }^{1,7}$ ) and those related to the psychosocial and socioeconomic context of a woman's life (e.g. maternal age, education, income, unemployment ${ }^{8}$ ), with mental health playing a part in both. Risk factors often cluster together and, generally, more risk factors predict worse outcomes for children ${ }^{3,9,10}$. Understanding the population-level prevalence and distribution of antenatal risk factors is important because it allows health care platforms to identify and address the factors that are amenable to influence and, in turn, potentially alter children's trajectories across the life course ${ }^{11}$.

Despite their seeming importance, Australian data on the prevalence and distribution of risk factors are scarce. A reason for this may be the challenges inherent in finding feasible and acceptable methods of data collection. Although Australian antenatal health services conduct risk factor screening, the information collected varies between clinics (personal communication Victorian antenatal birthing hospitals, 2012). This may be due to the Australian government's clinical practice guidelines for antenatal care ${ }^{12}$, which recommend screening of a broad range of health indicators, including medical history, lifestyle factors (e.g. smoking, alcohol use) and psychosocial factors (e.g. current and past mental health problems, domestic violence). However, the guidelines do not mention other known risks for poorer child outcomes such as poverty, low income or education ${ }^{13}$, and it can be up to the state, region or service provider to decide which characteristics to assess.

Even if antenatal consultations collected a more complete range of risk factor data, the sensitive nature of the standard antenatal interview has been shown to cause distress to some women $^{14}$. A recent ethnographic study, which collected observational and interview data from 34 Australian pregnant women using the health service, found that women perceived the psychosocial items within the standard screening assessment as unexpected, intrusive and uncomfortable ${ }^{14}$. This suggests there is room to increase the acceptability of risk assessment.

In 2012, we set out to design a randomized controlled trial (RCT) of sustained nurse home visiting (SNHV) (known as “right@home”, ISRCTN89962120), starting in pregnancy and delivered until children turn 2 years old. Delivered via the Australian primary health care 
Piloting an antenatal risk survey

system, the trial aims to improve the learning and development of children. Planning included consideration of which women would most likely benefit from an effective SNHV program (offering more support for parenting and providing an optimal home learning environment) based on their risk factor profile, and balanced against the pragmatics of antenatal data collection. To collect population-level data on the antenatal risk factors experienced by Australian women and identify those eligible for the SNHV RCT, there was a need for a simple tool that is feasible to implement and acceptable to women. To meet this need, we designed a simple, cross-sectional risk factor survey based on the existing antenatal and home visiting literature to assess a broad range of social determinants ${ }^{3,15,16}$.

This paper reports the development and piloting of the antenatal risk factor survey, whose purpose was to eventually screen over 5500 pregnant Australian women for recruitment into the RCT of SNHV. The first aim was to examine the (a) feasibility and (b) acceptability of the study-designed antenatal risk factor survey. In the context of using risk factors to define eligibility for the aforementioned RCT, the second aim was to examine whether survey risk factors co-occur with more sensitive risk factors reported in the standard private clinical interview.

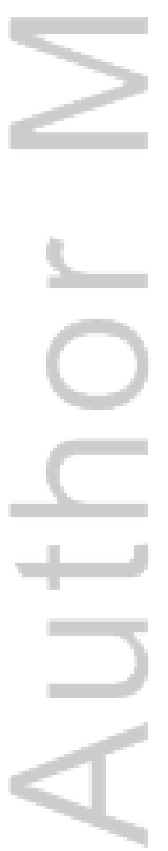

This article is protected by copyright. All rights reserved. 
Piloting an antenatal risk survey

\section{MATERIALS AND METHODS}

Study design: Most pregnant Australian women obtain free or heavily subsidized antenatal clinical care at large, public, birthing hospitals ${ }^{17}$. We designed a simple, cross-sectional risk factor survey based on the existing antenatal and home visiting literature ${ }^{3,15,16}$, intended for collection in the public waiting rooms of the hospital clinics. The survey could only be completed in waiting rooms because private clinical space was rarely available, and using a separate space could delay women for their appointments and reduce the number of women completing the survey at the same time (and thus the population coverage). Collecting the survey this way also reduced the burden of asking clinicians to collect the data. To ensure that the risk factor survey was not missing women with arguably more sensitive risk factors (e.g. alcohol and drug use, mental health problems etc.) collected by private clinical interview, we designed the survey to be linked with the hospital-collected antenatal electronic medical record (EMR) data collected by clinicians at the hospitals. In doing this, the intention was to use the survey items rather than the EMR risk factors to assess eligibility for the SNHV RCT.

Participants and setting: Participants were pregnant women attending antenatal clinics at two metropolitan Victorian hospitals on three consecutive days in February-March 2013. The hospitals were selected for their known provision of care to women living in areas with fewer socioeconomic resources, collection of electronic instead of paper medical records, collection of the same EMR data, and interest in participating. Women were eligible if they were pregnant and had sufficient English proficiency to provide informed consent and complete the survey.

Procedure: Trained researchers approached all women in the waiting rooms of the antenatal clinics and invited them to complete the pen and paper survey. To accommodate low literacy, researchers offered to go through the survey with each woman or to leave it with her to complete alone. Researchers checked all surveys for completeness. Informed consent included an option for linking the survey and hospital EMR data. Where women provided this consent, data were linked using the hospital-assigned unique identifier (Unit Record (UR) number) for each patient by the clinic manager.

Measures: The risk factor survey items are described in Table 1. <Insert Table 1 after this paragraph $>$ The EMR data from both hospitals comprised seven items: smoking, alcohol 
Piloting an antenatal risk survey

use, marijuana use, drug use, domestic violence, social issues (unspecified), history of mental health problems (all "yes"/“no") and the Edinburgh Postnatal Depression Scale (EPDS), which comprises ten 4-point items which ask about depressive symptoms over the preceding week $^{18}$. EPDS scores of $>9$ and $>12$ are cut-offs for moderate and high clinical depression symptoms, respectively. The EPDS has been validated and widely-used in clinical and community samples ${ }^{18}$. We note that within the hospitals included at this pilot stage, smoking was available from the EMR, collected by hospital staff, and thus not on the study-designed survey. However, we treated smoking as a survey risk factor because it was agreed by the study team that it would be acceptable to ask in the public setting whereas other EMR factors may be considered too sensitive to ask in this setting. Inclusion of smoking was then able to be recommended for our ongoing use of the risk factor survey.

Statistical Analysis: We tabulated frequencies of risk items to examine the distribution of survey characteristics and dichotomized items into risk factors based on the sample frequencies, whether they were associated with a differential frequency of risk of factors identified in the EMR, and the existing literature (see Table 1). The linked survey and EMR dataset were used to compare women who consented to EMR linkage with those who did not, using two sample t-tests for continuous outcomes and chi-square tests for categorical outcomes.

For $\operatorname{Aim} 1$, we assessed (a) feasibility by examining the proportion of women who had time to consent and complete the surveys before their appointment, and (b) acceptability by examining the proportion of women who completed the survey and the frequency of missing data for each item, assuming that single missing items meant women were not comfortable completing them. We also assessed how well the pilot sample represented the broader clinic population by comparing the EMR data for participating women with de-identified summary EMR data collected for all patients attending the clinic during the week of the pilot, which were compiled by the clinic managers. For $\operatorname{Aim} 2$, we created a count of risk factors $(0,1,2$ and e3), and a dichotomous variable "EMR risk" which categorized women with one or more EMR risk factor versus none. We used tabulations of the two variables to examine the cooccurrence of survey and EMR risk factors. 
Ethical approval: This study was approved by the Human Research Ethics Committees of The Royal Children's Hospital (HREC 32771), Northern Health (HREC P 20/12) and Peninsula Health (HREC/13/PH/13), all Melbourne, Australia.

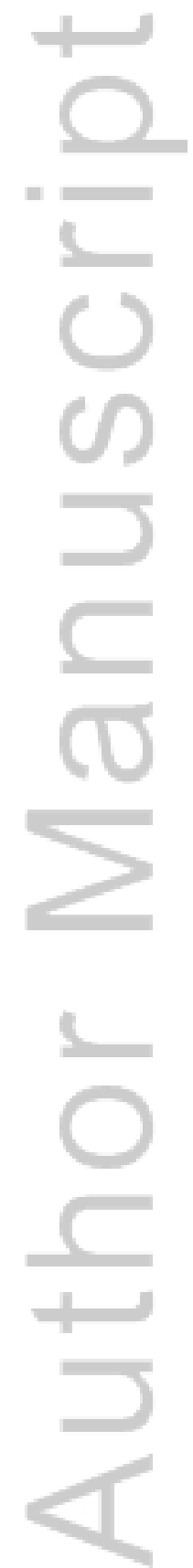

This article is protected by copyright. All rights reserved. 


\section{RESULTS}

Respondent characteristics: Two trained researchers approached all women attending the clinics. Of 195 women approached, 9 had insufficient English to complete the survey. Of the remaining 186 women, 166 (89\%) completed the survey and 20 declined. Eighty-four percent $(139 / 166)$ of responding women consented to the EMR data linkage, and these women had comparable demographics and risk factors to those who did not consent (Table 2), except that they were less likely to report having no support in pregnancy. $<$ Insert Table 2 after next paragraph>

The item asking about current employment was excluded from the final survey risk factor count as it was less discriminating of risk due to its high prevalence (see Table 2). Similarly, the two poverty proxy items (receiving monetary benefits from Centrelink program and having a Health Care card) were excluded from the final survey risk factor count because they were less discriminating of risk, due to: (i) their high prevalence (see Table 2), eligibility for these has the potential to change over time and differ across settings (states/countries) according to policy, (iii) there is the potential for confusion with other universal benefits such as the child care rebate which is also administered through Centrelink, and (iv) women who are eligible for these may not have arranged or know about these, particularly the Health Care card.

This resulted in ten dichotomous risk factors that were used to calculate the risk factor count: Current smoking; Young pregnancy ( $<23$ years old); No support (emotional, financial, practical) during pregnancy; Poor/fair/good general health (versus very good/excellent general health); Anxious mood; Not finishing high school; Not having a household income; A long-term illness; Living without another adult, and Never having had a job. Prevalence for each risk in the full sample $(\mathrm{n}=166)$ ranged from $2 \%-34 \%$.

Aim 1: Feasibility and Acceptability: All women were invited to complete the survey in the time they attended the clinic, the response fraction was high and no data were missing for any item. Table 3 compares the EMR data for participating women who consented to EMR data linkage, with a de-identified summary of the same EMR data for all clients attending clinic that week. $<$ Insert Table 3 after this paragraph $>$ As pilot participants could not be excluded from the whole clinic sample, they are represented in both columns. The pilot sample 
appeared representative of the whole clinic caseload, although the low reported prevalence of a number of the risk factors prevented formal comparison.

Aim 2: Co-occurrence between survey risk factor count and EMR risk (Table 4): The distribution of the risk factor count changed minimally ( $0-1 \%$ change in proportions) when women who did not consent to EMR data linkage were excluded. <Insert Table 4 after this paragraph $>$ As such, Table 4 presents only the women who provided consent for data linkage. It shows that $11 / 39(28 \%)$ of those with 1 risk factor, $6 / 23(26 \%)$ of those with 2 risk factors, and 16/30 (53\%) of those with e 3 risk factors had at least one EMR risk factor. Of the 36 women with EMR risk, 33 (92\%) were identified by a survey risk factor count of 1 or more, $22(61 \%)$ by a count of 2 or more, and $16(44 \%)$ by a count of 3 or more. Of the 103 women with no recorded EMR risk, 59 (57\%) recorded a survey risk factor count of 1 or more, $31(30 \%)$ a count of 2 or more, and $14(14 \%)$ a count of 3 or more survey risk factors.

This article is protected by copyright. All rights reserved. 


\section{DISCUSSION}

This pilot demonstrated that a short survey of 10 antenatal risk factors, which are known to be important for children's learning and development, was feasible to collect and acceptable to women when distributed in public hospital waiting rooms. Using cut-points of 1 or 2 risk factors appeared to identify the majority of women who disclosed more sensitive risk factors such as substance use, domestic violence and mental health problems. Collecting these sensitive items is still important within the clinical context (and not appropriate to be asked in public spaces); however, the adjunct psychosocial and socioeconomic questions provide important additional information that is often not part of the clinical interview yet critical to identifying women who may require additional support.

While the survey is simple, it provides a rapid method of gathering risk data in a public setting, and may be more acceptable to women than clinical assessments which can be perceived as intrusive ${ }^{14}$. It can be administered by non-clinical professional staff with a high response, which suggests utility in a range of settings. Based on the results, a risk factor count of 2 or more was chosen as the eligibility cut-point for participation in the larger SNHV RCT, as it captures the women in the top third of the risk factor count distribution and a majority proportion of those with EMR risk factors.

In terms of comparable data, the Growing Up in New Zealand study ${ }^{10}$ examined the prevalence and clustering of antenatal risk factors at the population-level. While differences in measures collected between ours and the NZ cohort limits some comparisons, more women in this sample were teenage parents (7\%, versus 5\% in the NZ cohort); fewer women had finished school (61\% versus 93\%), and women in this sample were more likely to report multiple risk factors (39\% reporting 2 or more compared with $33 \%$ in the NZ cohort). This suggests that the choice of hospital sites correctly recruited women with fewer resources and a greater need for support, and is supported by the sample's average Socio-Economic Indexes for Areas (SEIFA) score (978), which is lower than the Victorian average of 1004.

This study had some limitations. The design assumes that the survey risk factors predict children's learning and development trajectories on the basis of existing literature demonstrating these relationships ${ }^{1,3,7,9,10}$, but we were unable to examine this with data collection only being within the antenatal period. While the EMR data for participating women represented the weekly EMR clinic data, it is difficult to comment on 
representativeness due to the rarity with which some risk factors are recorded, e.g. the disclosure of substance use and domestic violence at both hospitals are known underrepresentations of the population risk levels ${ }^{3}$. The large SNHV RCT will respond to this and examine the validity of this survey at the population level, by comparing responses with indepth antenatal interviews (e.g. the mood items ${ }^{19}$ will be validated against the Depression, Anxiety, Stress Scale ${ }^{20}$ ). This will demonstrate how well the survey generalizes to pregnant women and the broader usefulness of the survey at the population level.

This survey identifies a large proportion of women as at-risk who are not assessed as at-risk by the EMR. This could be because the non-threatening survey questions identify women atrisk who are not disclosing the risks in the clinical encounter that generates the $\mathrm{EMR}^{14}$, or it could be because the survey is low in specificity. Similarly, using the survey to define eligibility for services (e.g. a cut-point of 1 or 2 risk factors) misses a smaller proportion of women who may, according to their EMR, benefit from more support. This suggests that a survey like this would be best used by clinicians in addition to (and not replacing) their standard quality history collection.

In conclusion, a simple survey of antenatal risk factors was feasible to collect in public waiting rooms and acceptable to women. If clinics have a mechanism for collecting these data for clinicians, the data could potentially assist clinicians in understanding the context of women's lives and consider the range of beneficial service responses (within and outside health) available for improving children's learning and development trajectories across the life course.

This article is protected by copyright. All rights reserved. 
Conflict of Interest: The authors declare that they have no conflict of interest.

Acknowledgments: The "right@home" sustained nurse home visiting trial is a research collaboration between the Australian Research Alliance for Children and Youth (ARACY); the Translational Research and Social Innovation (TReSI) Group at Western Sydney University; and the Centre for Community Child Health $(\mathrm{CCCH})$, which is a department of The Royal Children's Hospital and a research group of Murdoch Childrens Research Institute. "right@home" is funded by the Victorian Department of Education and Training, the Tasmanian Department of Health and Human Services, the Ian Potter Foundation, Sabemo Trust, Sidney Myer Fund, the Vincent Fairfax Family Foundation, and the National Health and Medical Research Council (\#1079418). The MCRI administered the research grant for the study and provided infrastructural support to its staff but played no role in the conduct or analysis of the trial. Research at the MCRI is supported by the Victorian Government's Operational Infrastructure Support Program. SG is supported by Australian National Health and Medical Research Council (NHMRC) Career Development Fellowship 1082922 and FM by NHMRC Early Career Fellowship 1037449 and Career Development Fellowship 1111160. The funding bodies had no role in relation to the design and conduct of the study; collection, management, analysis, and interpretation of the data; preparation, review, or approval of the manuscript; and decision to submit the manuscript for publication.

This article is protected by copyright. All rights reserved. 


\section{REFERENCES}

1. NSCDC. National Scientific Council on the Developing Child. Harvard University, Center on the Developing Child. Working Paper \#4: Early Exposure to Toxic Substances Damages Brain Architecture. http://developingchild.harvard.edu/resources/early-exposure-totoxic-substances-damages-brain-architecture/ Accessed 2 November 2015. 2006.

2. NSCDC. National Scientific Council on the Developing Child. Harvard University, Center on the Developing Child. Working Paper \#8: Maternal Depression Can Undermine the Development of Young Children. http://developingchild.harvard.edu/resources/maternaldepression-can-undermine-the-development-of-young-children/ Accessed 2 November 2015. 2009.

3. = Sabates R, Dex S. Multiple risk factors in young children's development. London: Centre for Longitudinal Studies, Institute of Education. 2012.

4. Santos IS, Barros AJ, Matijasevich A, et al. Cohort Profile Update: 2004 Pelotas (Brazil) Birth Cohort Study. Body composition, mental health and genetic assessment at the 6 years follow-up. Int J Epi. 2014;43:1437-1437f.

5. Sokol RJ, Delaney-Black V, Nordstrom B. Fetal alcohol spectrum disorder. JAMA. 2003;290:2996-2999.

6. Williams GM, O'Callaghan M, Najman JM, et al. Maternal cigarette smoking and child psychiatric morbidity: a longitudinal study. Pediatrics. 1998;102:e11-e11.

7. NSCDC. National Scientific Council on the Developing Child. Harvard University, Center on the Developing Child. Working Paper \#3: Excessive Stress Disrupts the Architecture of the Developing Brain. http://developingchild.harvard.edu/resources/wp3/ Accessed 2 November 2015. 2005.

8. Edwards B, Baxter J, Smart D, Sanson A, Hayes A. Financial disadvantage and children's school readiness. 2009.

9. Kiernan KE, Mensah FK. Maternal indicators in pregnancy and children's infancy that signal future outcomes for children's development, behaviour and health: evidence from the Millennium Cohort Study. York: University of York. 2009.

10. Morton SMB, Atatoa Carr PE, Grant CC, et al. Growing Up in New Zealand: A longitudinal study of New Zealand children and their families. Vulnerability Report 1 :

Exploring the Definition of Vulnerability for Children in their First 1000 Days. Auckland: Growing Up in New Zealand. Retrieved from http://www.growingup.co.nz/en.html; 2014.

11. McDonald M, Moore T, Goldfeld S. Sustained Home Visiting for Vulnerable Families and Children: A Literature Overview. Melbourne: Centre for Community Child Health (CCCH) \& Murdoch Children's Research institute (MCRI), 2012.

12. DoHA. Australian Health Ministers' Advisory Council, Clinical Practice Guidelines: Antenatal Care - Module 1. Australian Government Department of Health and Ageing, Canberra. http://www.health.gov.au/antenatal. Accessed 9 September 2016. 2012.

13. Dickerson A, Popli G. Persistent Poverty and Children's Cognitive Development: Evidence from the UK Millennium Cohort Study. Sheffield: Department of Economics, University of Sheffield, 2011.

14. Rollans M, Schmied V, Kemp L, Meade T. Digging over that old ground: an Australian perspective of women's experience of psychosocial assessment and depression screening in pregnancy and following birth. BMC Women's Health. 2013;13:18.

15. Chittleborough CR, Lawlor, D.A., Lynch, J.W.,. Prenatal prediction of poor maternal and offspring outcomes: implications for selection into intensive parent support programs. Matern Child Health J. 2012;16:909-920. 
16. Kemp L, Harris E, McMahon C, et al. Child and family outcomes of a long-term nurse home visitation programme: A randomised controlled trial. Arch Dis Child.

2011;96:533-540

17. AIHW. Australian Institute of Health and Welfare. Australian hospital statistics 201112. Health services series no. 50. Canberra. 2013.

18. Murray L, Carothers AD. The validation of the Edinburgh Post-natal Depression Scale on a community sample. Br J Psychiatry. 1990;157:288-290.

19. Matthey S, Valenti B, Souter K, Ross-Hamid C. Comparison of four self-report measures and a generic mood question to screen for anxiety during pregnancy in Englishspeaking women. J Affect Disord. 2013;148:347-351.

20. Henry JD, Crawford JR. The short-form version of the Depression Anxiety Stress Scales (DASS-21): construct validity and normative data in a large non-clinical sample. $\mathrm{Br} \mathrm{J}$ Clin Psychol. 2005;44:227-239.

21. Australian Bureau of Statistics Census of Population and Housing: Socio-Economic Indexes for Areas (SEIFA), Australia - DataPacks 2011.

http://www.abs.gov.au/websitedbs/censushome.nsf/home/seifa2011. Accessed 18 December 2015 [Internet]. 2011.

22. Kiernan KE. Becoming a Young Parent: A Longitudinal Study of Associated Factors. Br J Sociol. 1997;48:406-428.

23. Sanson AV, Hawkins MT, Misson S. The Development and Validation of Australian Indices of Child Development_-Part II: Validity Support. Child Indicators Research. 2010;3:293-312.

24. ONS. UK Office for National Statistics. Census 2001 Key Statistics 21: Long Term Illness. http://data.london.gov.uk/dataset/census-2001-key-statistics-21-long-term-illness. Accessed 18 December 2015. UK Census. London: Office for National Statistics; 2001. 


\section{TABLES}

\section{Table 1. Description of survey items}

\begin{tabular}{|c|c|}
\hline Item & Description \\
\hline UR number & Unique hospital identifier \\
\hline Gestat & In weeks \\
\hline First ch & "yes" versus "no"; if yes, date first child was born \\
\hline \multirow[t]{3}{*}{ Postcode/zip code } & For each participant, we merged data from the Socio-Economic Indexes for Areas (SEIFA) Index of Relative \\
\hline & Disadvantage, a national area level index derived from census data for all individuals living in a postcode, with \\
\hline & higher scores indicating greater advantage ${ }^{21}$. \\
\hline Young pregnancy & Calculated from year of birth and dichotomized into $<23$ years versus e23 years ${ }^{22}$ \\
\hline Living with another adult & "yes" versus "no" \\
\hline Support in pregnancy & For example, financial, emotional or practical ("yes" versus "no") \\
\hline Global health & Single 5-point item ("poor" to "excellent") from the self-reported Short Form-6, dichotomized into \\
\hline & "poor/fair/good" versus "very good/excellent" 23 \\
\hline
\end{tabular}

This article is protected by copyright. All rights reserved. 


\begin{tabular}{|c|c|}
\hline Item & Description \\
\hline Long-term illness & Health problem or disability that limits daily activities (“yes"/“no"), drawn from the UK Census 2001 Census ${ }^{24}$ \\
\hline Anxious mood & $\begin{array}{l}\text { Matthey two-item Generic Mood Question, which has shown good correlation with longer, validated anxiety } \\
\text { measures including the Edinburgh Postnatal Depression Scale (EDPS) and the Hospital Anxiety Depression Scale } \\
19\end{array}$ \\
\hline Education & $\begin{array}{l}\text { Highest level of school completed, dichotomized into " }<\text { Year } 12 \text { " versus "completed Year 12" reflecting } \\
\text { completion of secondary level education in Australia }\end{array}$ \\
\hline Income & Person in household who currently has paid work/earns an income ("yes"/“no") \\
\hline Currently employed & Currently working ("full-time"/“part-time"/“no"). \\
\hline Ever worked & "yes" versus "no" \\
\hline Poverty & Receiving monetary benefits from the Australian Department of Human Services Centrelink program ("yes" \\
\hline & versus "no"); and having a Health Care card which is means-tested and subsidizes health services and \\
\hline 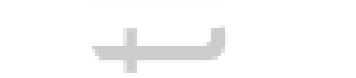 & prescriptions (“yes" versus "no"), both chosen as proxy measures for poverty. \\
\hline
\end{tabular}

This article is protected by copyright. All rights reserved. 
Table 2: Participant survey characteristics and risk factors

\begin{tabular}{|c|c|c|c|c|}
\hline & \multirow{2}{*}{$\begin{array}{l}\text { All women } \\
\qquad \mathrm{N}=166\end{array}$} & \multicolumn{2}{|c|}{ Consented to linking } & \multirow[b]{2}{*}{ p-value } \\
\hline & & $\begin{array}{c}\text { Yes } \\
(n=139)\end{array}$ & $\begin{array}{c}\text { No } \\
(\mathrm{n}=27)\end{array}$ & \\
\hline Gestation (weeks), mean (SD) & $29.8(8.1)$ & $30.2(7.7)$ & $27.5(9.9)$ & 0.12 \\
\hline First time parent, n (\%) & $88(53)$ & $76(55)$ & $12(44)$ & 0.33 \\
\hline SEIFA, mean (SD) & $978.3(66.2)$ & $977.7(64.8)$ & $981.4(74.4)$ & 0.79 \\
\hline Age $<23$ years, $\mathrm{n}(\%)$ & $25(15)$ & $24(7.3)$ & $1(3.7)$ & 0.07 \\
\hline Not living with an adult, $\mathrm{n}(\%)$ & $3(2)$ & $2(1)$ & $1(4)$ & 0.42 \\
\hline No support, n (\%) & $14(9)$ & $8(6)$ & $6(22)$ & 0.005 \\
\hline Good/Fair/Poor health, n (\%) & $56(34)$ & $46(33)$ & $10(37)$ & 0.69 \\
\hline Long term illness, $\mathrm{n}(\%)$ & $10(6)$ & $8(6)$ & $2(7)$ & 0.74 \\
\hline Anxious mood, n (\%) & $11(7)$ & $9(6)$ & $2(7)$ & 0.86 \\
\hline$<$ Year 12 Education, n (\%) & $46(28)$ & $38(27)$ & $8(30)$ & 0.81 \\
\hline No income, $\mathrm{n}(\%)$ & $12(7)$ & $8(6)$ & $4(15)$ & 0.10 \\
\hline Not currently working, n (\%) & $100(61)$ & $85(61)$ & $15(58)$ & 0.54 \\
\hline Never had a job, n (\%) & $16(10)$ & $14(10)$ & $2(7)$ & 0.66 \\
\hline Centrelink benefits, $\mathrm{n}(\%)$ & $71(43)$ & $60(43)$ & $11(44)$ & 0.93 \\
\hline Health Care Card, n (\%) & $55(33)$ & $49(35)$ & $6(22)$ & 0.19 \\
\hline
\end{tabular}

This article is protected by copyright. All rights reserved. 


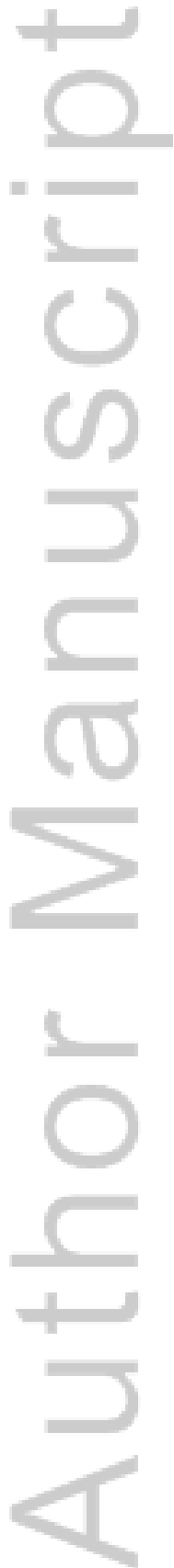

This article is protected by copyright. All rights reserved. 
Table 3: Distribution of EMR risk factors in pilot sample and weekly clinic load

\begin{tabular}{lcccc}
\hline EMR risk factors & \multicolumn{2}{c}{ Hospital $1, \mathrm{n}(\%)$} & \multicolumn{2}{c}{ Hospital 2, $\mathrm{n}(\%)$} \\
& Pilot & Whole clinic & Pilot & Whole clinic \\
& $\mathrm{n}=81$ & $\mathrm{~N}=400-405$ & $\mathrm{n}=58$ & $\mathrm{~N}=173-194$ \\
\hline Smoking & $9(11)$ & $52(13)$ & $17(29)$ & $51(26)$ \\
EPDS community cut-off $>9$ & $5(6)$ & $29(7)$ & $6(12)$ & $30(17)$ \\
EPDS clinical cut-off $>12$ & $1(1)$ & $15(4)$ & $4(8)$ & $17(10)$ \\
History of mental health problems & $8(10)$ & $39(10)$ & $10(17)$ & $34(18)$ \\
Alcohol abuse & $3(4)$ & $9(2)$ & $1(2)$ & $6(3)$ \\
Marijuana use & $2(3)$ & $6(2)$ & $1(2)$ & $9(5)$ \\
Drug use & $1(1)$ & $1(0)$ & $2(4)$ & $10(5)$ \\
Domestic violence & $3(3)$ & $20(5)$ & $14(24)$ & $37(19)$ \\
\hline
\end{tabular}

$\mathrm{EMR}=$ Electronic Medical Record 
Table 4: Co-occurrence between survey risk factor count and EMR risk

\begin{tabular}{|c|c|c|c|}
\hline Risk factor & Women identified & \multicolumn{2}{|c|}{ EMR risk factors ${ }^{b}$} \\
\hline \multirow[t]{3}{*}{ score $^{\mathrm{a}}$} & (complete data $n=139$ ) & & \\
\hline & & Yes $(n=36)$ & No $(n=103)$ \\
\hline & n (column \%) & n (row \%) & n (row \%) \\
\hline 0 & $47(34)$ & $3(6)$ & $44(94)$ \\
\hline 1 & $39(28)$ & $11(28)$ & $28(72)$ \\
\hline 2 & $23(17)$ & $6(26)$ & $17(74)$ \\
\hline e3 & $30(22)$ & $16(53)$ & $14(47)$ \\
\hline
\end{tabular}

\section{$\mathrm{EMR}=$ Electronic Medical Record}

${ }^{\mathrm{a}}$ Count of number of risk factors from: current smoking, young pregnancy ( $<23$ years old), no support (emotional, financial, practical) during pregnancy, poor/fair/good general health (versus very good/excellent general health), anxious mood, not finishing high school, not having a household income, a long-term illness, living without another adult, and never having had a job.

${ }^{\mathrm{b}}$ One or more maternal health concerns identified from hospital records: alcohol use, drug use, marijuana use, social issues, domestic violence, a history of mental health problems, or EPDS score $>12$. 


\section{University Library}

\section{- M M N E R VA A gateway to Melbourne's research publications}

Minerva Access is the Institutional Repository of The University of Melbourne

Author/s:

Price, AMH;Bryson, HE;Mensah, F;Kemp, L;Bishop, L;Goldfeld, S

Title:

The feasibility and acceptability of a population-level antenatal risk factor survey: Crosssectional pilot study

Date:

2017-06-01

Citation:

Price, A. M. H., Bryson, H. E., Mensah, F., Kemp, L., Bishop, L. \& Goldfeld, S. (2017). The feasibility and acceptability of a population-level antenatal risk factor survey: Crosssectional pilot study. JOURNAL OF PAEDIATRICS AND CHILD HEALTH, 53 (6), pp.572-577. https://doi.org/10.1111/jpc. 13510.

Persistent Link:

http://hdl.handle.net/11343/292712 